\title{
Statistical Research of Structural Shift in Unemployment of Youth in Regions of Russia
}

\author{
Vladimir Markov² \\ 1Samara State University of Economics, Samara, Russia \\ 2 Plekhanov Saratov Socio-Economic Institute, Saratov, Russia \\ Correspondence: Samara State University of Economics, 443090, Russia, Samara, Sovetskoi Armii Street, 141 \\ Email: yurijchistik@yandex.ru
}

Olga Chistik ${ }^{1}$

\section{Doi:10.5901/mjss.2015.v6n6s3p470}

\section{Abstract}

The authors analyze the performance of structural changes in youth unemployment in the regions of Russia in 2005-2013. The object of this study is the youth labor market, its regional and age-related structural changes in the level of unemployment using an example of young people aged 15-19 and 20-29. The purpose of this research - to perform statistical assessment and quantitative analysis of structural changes in youth unemployment and its role in unemployment formation in Russia in 20052013. The article represents an overview and comparison of integral factors of structural changes, and then selects the most statistically informative. It is revealed that there were the strongest age-related changes in unemployment in 2011-2012 and 2007-2009 in the Russian economy. It is shown that the role of youth in the Russian indicators of unemployment is very high, but fluctuations from year to year in the group are below. After applying the integral factor of structural changes NAV, the authors suggest the decomposition technique of structural changes in the active and passive components. With the active component of the structural change it is justified that the factors of unemployment are different for different ages, the effects of economic shocks of the crisis for young people are less pronounced than for the total economically active population in the regions of Russia. Using the active components of structural changes the authors grouped the regions of Russia and identified regions with effective policies to reduce youth unemployment.

Keywords: statistical indicators of structural changes, youth unemployment, regional structural changes, regional labor market, the impact of economic shocks on unemployment.

\section{Introduction}

The study of complex socio-economic phenomena, among which is the use of labor resources in the economy, requires understanding of the internal structure of the phenomenon and the links between its constituent units.

The structure of the labor market is achievement of the economic system that is formed by relationships between its elements (Sukharev, 2010, p.41). In theory, the structural change in the economy can be regarded as a qualitative change in the economic system, which consists of replacing the pre-existing relationships between its constituent parts with new ones. Structural changes are due to the uneven development of various elements of the economic system and indicate changes in the needs of the subjects of economic life and in placing economic resources (Krasilnikov, 2005) .These statements apply to most macroeconomic processes. Macroeconomic parameters, particularly those associated with production, investment, employment, have a high inertia across the country. The dimension of unemployment, in contrast to the allied employment rate is much lower, that it even in theory implies both a greater variability in dynamics and variability, structural differences within the population.

If the object of investigation is the country in its regional context, as well as the desired indicator is unemployment by age groups, so the application value of the structural analysis increases manifold. The policy to promote youth employment, based on understanding of structural unemployment parameters, is a key element in reducing social tensions and has long-term effects, as economic activity involves the population with the highest employment potential. With regard to the unemployed as a whole, this means promoting formation and maintenance of motivation and skills necessary for employment (Chistik, 2014, p.105). Therefore, the results of the structural analysis of unemployment provide an opportunity for development of targeted measures to improve the state of the labor market and to overcome its structural imbalances. 


\section{Method}

Unemployment is the most sensitive indicator of socio-economic transformations, and youth unemployment is an indicator of social welfare and structural balance of the labor market.

In many cases, to study the structure of socio-economic processes it is necessary not only to determine the proportion of parts and identify a certain period of changes, but also give a summary quantitative characterization of structural changes over time or differences between two homogeneous structures in space.

Statistics has a number of indicators that provide quantitative assessment of structural differences. Most of them are built on the principle of a linear medium or standard deviation. The most preferable indicators, from the standpoint of economic sense and valuation ratios, are K. Gateva's absolute structural changes:

$N A V=\frac{1}{2} \sum\left|d_{2}-d_{1}\right|$ - the linear one is the most common in international practice of the structural analysis and is called "the coefficient of structural changes NAV» (Norm of Absolute Values) [Dietrich, 2009], or Michaely-index or Stoikov-index (Stoikov, 1966, Prokofievetal., 2008):

$$
\sigma_{\text {norm }}=\sqrt{\frac{1}{2} \sum\left(d_{2}-d_{1}\right)^{2}} \quad \text { - quadratic; } \quad K i=\sqrt{\frac{\sum_{i}\left(d_{2}-d_{1}\right)^{2}}{\sum_{i} d_{2}{ }^{2}+\sum_{i} d_{1}{ }^{2}}} \text { - integral. }
$$

The obvious disadvantage of the integral factor of structural differences $\left(\mathrm{K}_{\mathrm{i}}\right)$ is the lack of real economic sense of the denominator.

To quantify the significant differences of structural parameters for a number of years, you can also use other authors' coefficients of structural differences ("Regional Statistics", 2001):

A. Salai-index $\left(I_{c}\right): I_{c}=\sqrt{\frac{\sum_{i}\left(\frac{d_{2}-d_{1}}{d_{2}+d_{1}}\right)^{2}}{n}}$

Lilien-modified index [Driver 1996]:

$$
M L I=\sqrt{\sum d_{1} \times d_{2} \times\left(\ln \frac{d_{2}}{d_{1}}\right)^{2}}
$$

where $d_{2} u d_{1}$ - specific values of gradation (share) in two structures.

These indicators can be set from 0 to 1 and are traditionally used to assess significant differences of structural indicators, as their meaning is based upon actual measure of component discrepancy values of two structures with their maximum value. Nevertheless, all these factors have conventions because there is a lack of real economic sense of denominator relations and expression, taken from the root.

However, there are mathematical proofs (Tumasjanand Vasilevskaja, 2006, p.61) that all scaled indicators are not proportional to the angle of rotation from the vector-structure $x$ to the vector-structure $y$, and we know the criterion according to which indicators, constructed on the basis of the average linear or quadratic deviation, are inappropriate to use in case if the maximum value of shares exceeds the minimum studied one more than twice. Therefore, as an alternative gauge it is proposed to use the cosine of the angle between the vectors of structures, called "the coefficient of similarity" or "the cosine factor» (Shimovet al., 1996, p.30).

In conventional signs, adopted in the statistical analysis, the coefficient of the cosine is:

$$
E=\sum \frac{d_{1} d_{2}}{\sqrt{\sum d_{1}^{2} \sum d_{2}^{2}}} \text {. }
$$

The coefficient of the cosine is completely determined by the angle of rotation between the studied structures and varies from 1 (complete coincidence of structures) to 0 (with orthogonal structures).

All of the above indicators are scaled in the range of $0-1$, but for ease of the analysis, the authors transform them into percentages. In addition, for a one-way interpretation it is necessary to transform the coefficient-cosine into 1 - $E$.

In scientific and educational literature one generalized assessment of the impact of structural factors on the change of the studied phenomenon in time or space is generally recognized from studies of structural changes or differences. With rare exception, the scientists do not examine the change effect of each share of the aggregate change in the social phenomenon - the carrier of this population: neither in terms of power influence, nor the direction of the impact position. Moreover, so far the generalization issues of such structural changes in terms of age unemployment have not been considered, although their formulation and solution seem to be very relevant.

In this regard, the modern interpretation in assessment of active and passive components of structural changes is not noteworthy (Prokofiev, 2006, p.121-122). It was proved, that the change in the share of each population may be due 
to changes of this part, as well as changes of its addition to the whole population. In this case, the first change in the share is called "active change", and the second one - "passive change." In the case of youth unemployment, this means that the spatial distribution of the number of unemployed aged 15-29 changes over time, and, firstly, the role of some regions in this case can be as an active increment / decrease in the number of unemployed young people, leading to an increase or decrease in the role of this region in the parameters of the Russian unemployment. Secondly, the role of a particular region can passively change due to changes in the number and proportion of the unemployed in other regions of Russia.

Theoretically, an addition of any portion to the entire population should be regarded as a subset consisting of one or a plurality of other portions of the original population.

In the next part of this study the authors examine theoretical decomposition foundations of the coefficient NAV on active and passive components, and each of them - on the positive and negative components.

\section{The Results of Empirical Research and Conclusions ${ }^{1}$}

\subsection{Generalizing indicators of structural changes}

The aim of this work is to study structural changes in youth unemployment in 77 regions of Russia for the period 20052013. (Statistical data: Federal State Statistics Service "Household Survey on Employment", 2014). From a population of subjects in the Russian Federation the authors exclude the regions with missing data or extreme (due to a small number of young people) values. The unemployed youth is a number of economically active population of 15-29 years old in the category of the unemployed by ILO methodology.

The preliminary studies of descriptive statistics and the basic laws of youth unemployment allow to choose two (Markov, 2015) analysis of material aspects in generalizing indicators of structural changes:

- The role of unemployed youth in age structure changes in unemployment and the changing role of some regions in the Russian structure of the unemployed;

- The trend of structural changes in unemployment of 15-29-year-old population in Russian regions.

Table 1. Structural changes in the age of the unemployed in the regions of Russia for 2005-2013

\begin{tabular}{|c|c|c|c|c|c|}
\hline \multirow{2}{*}{ Period } & \multicolumn{5}{|c|}{ Coefficient, \% } \\
\cline { 2 - 6 } & NAV & $K_{u}$ & $I_{c}$ & $M L I$ & $1-E$ \\
\hline $2006 / 2005$ & 1,90 & 2,81 & 5,79 & 1,89 & 0,08 \\
\hline $2007 / 2006$ & 1,94 & 3,02 & 3,35 & 2,04 & 0,09 \\
\hline $2008 / 2007$ & 2,79 & 4,36 & 9,65 & 2,93 & 0,18 \\
\hline $2009 / 2008$ & 3,66 & 5,73 & 8,24 & 3,87 & 0,29 \\
\hline $2010 / 2009$ & 0,79 & 1,15 & 1,75 & 0,79 & 0,01 \\
\hline $2011 / 2010$ & 1,68 & 2,37 & 3,33 & 1,64 & 0,06 \\
\hline $2012 / 2011$ & 2,43 & 3,45 & 4,85 & 2,41 & 0,10 \\
\hline $2013 / 2012$ & 1,49 & 2,07 & 3,06 & 1,46 & 0,04 \\
\hline $\mathbf{2 0 0 9 / 2 0 0 5}$ & $\mathbf{6 , 4 3}$ & $\mathbf{8 , 8 1}$ & $\mathbf{8 , 5 6}$ & $\mathbf{5 , 9 8}$ & $\mathbf{0 , 3 8}$ \\
\hline $\mathbf{2 0 1 3 / 2 0 0 8}$ & $\mathbf{8 , 0 6}$ & $\mathbf{1 1 , 0 0}$ & $\mathbf{1 7 , 4 0}$ & $\mathbf{7 , 4 0}$ & $\mathbf{0 , 5 6}$ \\
\hline
\end{tabular}

In Table 1, the authors separately calculate structural changes in the age structure of the unemployed in the pre-crisis and post-crisis period: 2009 compared to 2005 and 2013 to 2008.

As we can see, in five-year intervals aggregated data give a more complete picture of structural changes: in the pre-crisis years age variations in the structure of the unemployed were much lower. It turns out that after 2008 the age structure of the unemployed has changed more. Unfortunately, these factors do not show the reasons and factors (age) of structural changes. At the same time, there is the most clearly discrepancy in Szalai-index: $17.4 \%$ to $8.6 \%$, and by the coefficient Ki.

Comparison of age changes in the structure of the unemployed is shown in Figure 1.

\footnotetext{
${ }^{I}$ This section was conducted at the Institute of Agrarian Problems of RAS with the financial support from the Russian Scientific Foundation (RSF), project \# 14-18-02801.
} 


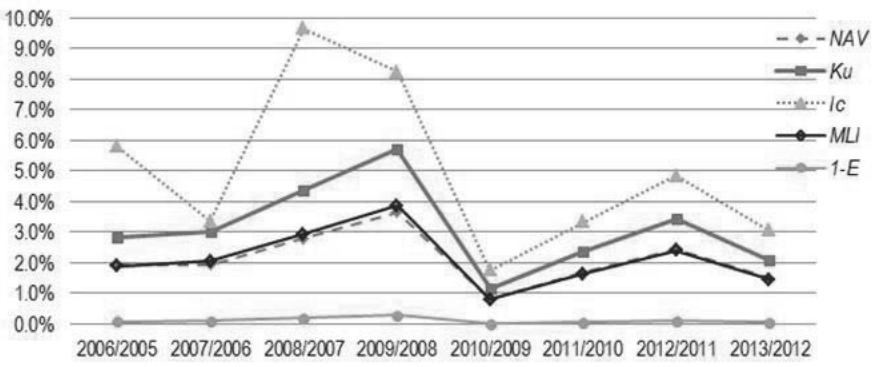

Figure 1. Structural changes in 2005-2013. in the age structure of the unemployed in Russia, the comparison of informative coefficients.

The generalizing indicators of structural changes in Fig. 1 indicate that the most dramatic changes in the average age of the unemployed in the Russian economy took place in 2007-2009 and 2011-2012. Consequently, the impact of the shocks of the economic crisis is an uneven effect on different age groups of the economically active population and had a logged effect in 2012. From the point of view of the final change in the average age of the unemployed as a result of divergent changes in the age groups up to 2007, it had decreased (35.2 years in 2005, 34.9 and 34.6 in 2006 and 2007 respectively), and after 2008 there was an annual growth (to 36.5 years in 2013), as it is shown in Fig. 2. The role of youth in the pre-crisis lowering the average age is significant: since the number of unemployed in the age groups 15-19 and 20-29 years declined more slowly than in other groups, the average age decreased. Beginning with 2008, on the contrary, the number of unemployed increased in all categories, but due to the greater number of working-age population structural changes have led to some "aging" of unemployment. In general it can be concluded that the role of youth in Russian indicators of unemployment is very high, but fluctuations of unemployment among young people are below. Therefore, the list of factors determining the dynamics of unemployment is specific, among others the effects of economic shocks of the crisis are less registered than for the total economically active population in regions of Russia.

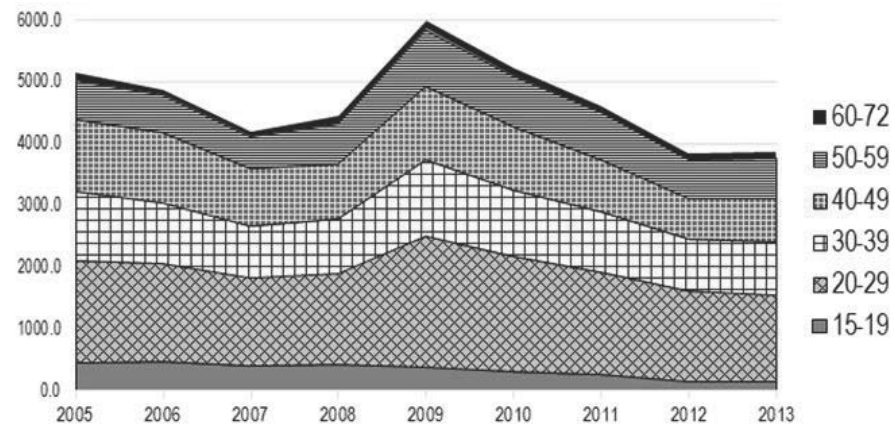

Figure 2. The number of the unemployed by age groups in Russia, thousands of people, in 2005-2013.

Then the authors analyze in more detail the chain (on related data) of structural changes of youth unemployment in Russian regions (Figure 3). 


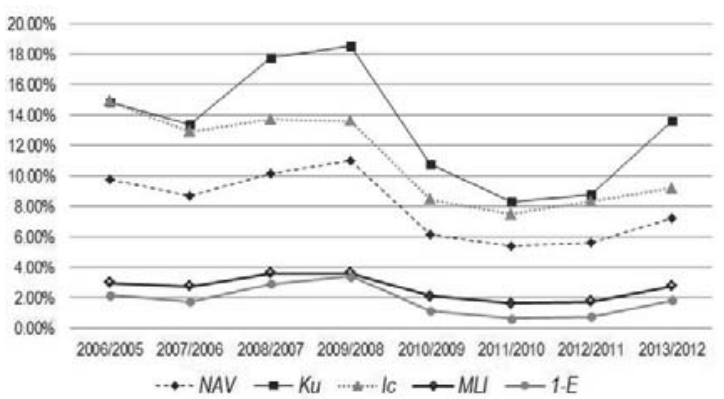

Figure 3. Chain structural changes of youth unemployment - 15-29 years old between regions of Russia in 2005-2013, the comparison of informative coefficients.

The data in Figure 3 indicate that in addition to the age differentiated response to the crisis of unemployment, clustering changes characterize regional indicators. Regional differences had maximum changes from 2007 to beginning of 2010, and then began to grow in 2013.

In terms of amplitude of oscillation, Salai-index and K.Gateva-integral coefficient are more sensitive to changes, and the coefficient of the cosine is too robust. Liliana-index is almost identical to the levels of the coefficient NAV in assessing age structural changes between regions of Russia and similar to it in form. The authors use the coefficient NAV, which in addition to other advantages, also has the ability to decompose the reasons and direction of changes.

\subsection{Active and passive components of structural changes}

After summarizing the characteristics of structural changes in unemployment by age and region, the authors will continue the detailed analysis of endogenous factors which determine the final configuration changes, including changes due to youth unemployment.

In formation of the coefficient NAV in a mixed form, active and passive increments take place in increments of shares with partial mutual destruction of each other. The linear coefficient NAV initially separates the active part from the passive one and the active part in the composition does not emit positive and negative components.

Under completely different situations this coefficient, and other of the analyzed factors above with structural changes that have the same disadvantages, can give the same or nearly the same values. In this regard, it is interesting to study the separate assessment of the positive and negative active component of structural changes and the proportion of each component in its value. This ensures the possibility of presenting a sufficiently complete picture of the trends in development of regional structural changes in youth unemployment: as in the direction of their growth so as in the direction of reduction depending on the active change in unemployment in certain regions. In the future, it provides an opportunity to identify and forecast trends of structural changes.

Let us analyze the key components of the coefficient NAV - an active component of structural changes NAV_A on youth unemployment in the regions of Russia.

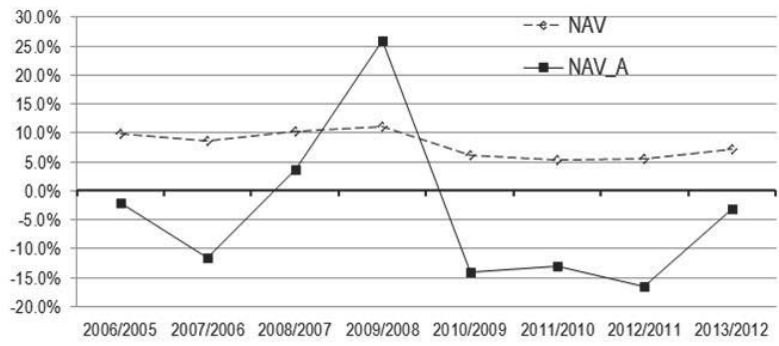

Figure 4. Active changing role of the regions of Russia in formation of youth unemployment and the overall structural changes in 2005-2013. 
The active components of structural changes in Figure 4 can be understood as potential changes in the regional structure of youth unemployment in case of abstracting from the impact of regions on each other. Thus, if the population of regions, that is the country, would not be closed, i.e. individual increments of the unemployed would not be associated with reduction, the fluctuations of unemployment in Russia would be very large.

Thus, according to the schedule it may be concluded that there was an overall trend of the active reducing in youth unemployment in all regions except for the period of 2007-2009. Moreover, this decrease in total, for example, in 2012 would amount to $15 \%$ of all unemployed persons aged 15-29. However, as a part of NAV, in addition to the active component, there is also a passive one, which reduces potential structural changes in proportions of regional unemployment to actual variations in the range of $5-10 \%$. Trends in unemployment economically are more inertia and cancel the active change in favor of reducing the unemployment rate of young people.

Indexes of the common structural change and its active components are presented in Table. 2. Also there are regional average values of the active pulse on growth or reduction of youth unemployment. Comparing the penultimate and last columns, one can argue about the higher intensity in reducing youth unemployment in the average region, especially in the post-crisis years.

Table 2. Detailed structural changes in regional unemployment of the Russian youth 15-29 years old in 2005-2013.

\begin{tabular}{|c|c|c|c|c|c|}
\hline \multirow{2}{*}{ Period } & \multicolumn{5}{|c|}{ Coefficient NAV and components of NAV, \% } \\
\cline { 2 - 6 } & $\begin{array}{c}\text { NAV, in Russian } \\
\text { Federation }\end{array}$ & $\begin{array}{c}\text { NAV_A in Russian } \\
\text { Federation }\end{array}$ & $\begin{array}{c}\text { regional average } \\
\text { NAV_A } A\end{array}$ & $\begin{array}{c}\text { regional average } \\
\text { NAV_A } A^{+}\end{array}$ & $\begin{array}{c}\text { regional average } \\
\text { NAV_A } A\end{array}$ \\
\hline $2006 / 2005$ & 9,79 & $-2,13$ & $-0,03$ & 0,24 & $-0,26$ \\
\hline $2007 / 2006$ & 8,71 & $-11,51$ & $-0,15$ & 0,17 & $-0,27$ \\
\hline $2008 / 2007$ & 10,20 & 3,68 & 0,05 & 0,26 & $-0,24$ \\
\hline $2009 / 2008$ & 11,04 & 25,94 & 0,34 & 0,42 & $-0,22$ \\
\hline $2010 / 2009$ & 6,20 & $-14,09$ & $-0,18$ & 0,08 & $-0,25$ \\
\hline $2011 / 2010$ & 5,41 & $-13,08$ & $-0,17$ & 0,06 & $-0,21$ \\
\hline $2012 / 2011$ & 5,63 & $-16,54$ & $-0,21$ & 0,07 & $-0,27$ \\
\hline $2013 / 2012$ & 7,23 & $-3,10$ & $-0,04$ & 0,20 & $-0,18$ \\
\hline
\end{tabular}

The degree of regional differentiation activities in the youth labor market will be analyzed using the non-parametric indicators. To do this, for each structural change (on related years, such as 2006/2005) we will isolate the active component in each region, and then rank the regions in descending order of the change magnitude. Thus, we obtain a set of data on 77 regions of the Russian Federation for the entire study interval. Next, we will define the first and ninth decile. In this case, in contrast to the analysis of income inequality, decile №1 will include regions with a maximum increment of active unemployed youth, and decile №9 - with the maximum activity decrease. In other words, the ninth decile cuts $10 \%$ of the best regions in each year, and the first decile - 8 worst regions $(77 / 10=8)$.

For a meaningful comparison of regional progress in reducing youth unemployment we will determine the average active change in each decile, as well as establish the corridor of fluctuations in decile - the actual minimum and maximum.

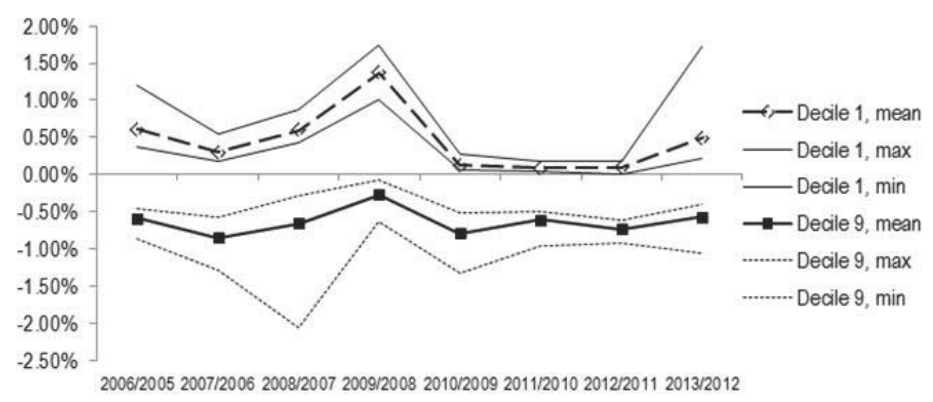

Figure 5. The ranges of active structural changes on youth unemployment in the top $10 \%$ best and $10 \%$ worst regions in Russia. 
The composition of deciles is heterogeneous by years, it means that not all regions successfully reduce youth unemployment in some years. To understand the fact which regions are most successfully and actively reduce youth unemployment, which effectively cope with the consequences of the crisis, and which are the hardest to survive its effects, the authors will represent a table with a list of the regions most likely to be in the ninth and the first decile. The presence in both tables is not an error, but only reflects the high variability, that is, for example, the transition from effectively reduction of youth unemployment in a given year, to its sharp increase in the second year. Nevertheless, the frequency of contact with a particular decile can be interpreted as accumulation of rating points for leadership development (successful control of unemployment) or lag (uncontrollable growth).

Table 3. The list of regions, which more than 1 time fell into extreme decile on active growth or reduction of youth unemployment in 2005-2013.

\begin{tabular}{|l|c|l|c|}
\hline The list of regions in 2005-2013 within the first decile & Frequency, times & The list of regions in 2005-2013 in the ninth & Frequency, times \\
\hline The Republic of Dagestan & 4 & The Republic of Bashkortostan & 5 \\
\hline St. Petersburg & 4 & Krasnodar region & 4 \\
\hline Moscow region & 3 & Krasnoyarsk region & 4 \\
\hline Chelyabinsk region & 3 & Moscow & 3 \\
\hline Moscow & 3 & St. Petersburg & 3 \\
\hline Trans-Baikal region & 3 & Altai region & 3 \\
\hline Krasnoyarski Krai & 3 & The Republic of Tatarstan & 3 \\
\hline Saratov region & 2 & The Republic of Dagestan & 3 \\
\hline Kaliningrad oblast & 2 & Moscow region & 3 \\
\hline Tula oblast & 2 & Chelyabinsk region & 3 \\
\hline Volgograd region & 2 & Nizhny Novgorod region & 2 \\
\hline The Republic of Sakha (Yakutia) & 2 & Saratov region & 2 \\
\hline Arkhangelsk oblast & 2 & Vladimir region & 2 \\
\hline Sverdlovsk Region & 2 & Perm region & 2 \\
\hline Perm region & 2 & Primorski Krai & 2 \\
\hline The Republic of Udmurtia & 2 & Rostov region & 2 \\
\hline The Republic of Bashkortostan & 2 & Volgograd region & 2 \\
\hline Kabardino-Balkar Republic & 2 & Sverdlovsk region & 2 \\
\hline Omsk region & 2 & Voronezh region & \\
\hline
\end{tabular}

The regions with the most successfully controlled reduction of youth unemployment are the republics of Bashkortostan and Tatarstan, the Krasnodar region. Unemployment shocks manifest themselves in a large oscillation of youth unemployment in the city of Moscow, Moscow and Chelyabinsk regions - the frequency of their occurrence in the leaders and outsiders is the same. The same is true for St. Petersburg. To outsiders we can assign unambiguous Trans-Baikal Territory.

Our analysis of structural changes, as well as separation of their active components is a basis which can enhance the quality of the state employment policy, focus and describe the role of some regions, as well as structural changes linked to changes in the main macroeconomic indicators.

\section{Acknowledgements}

This section was conducted at the Institute of Agrarian Problems of RAS with the financial support from the Russian Scientific Foundation (RSF), project \# 14-18-02801.

\section{References}

Krasilnikov, O. Ju. (2005). Problems of structural changes in the economy. Jekonomist. No.8, p.52-58.

Markov, V.A. (2015). Regional structural shifts in the Russian regions on youth unemployment. Proceedings of the International scientific and practical conference, 24-30 December 2014.Saratov, p.53-57.

Federal State Statistics Service. (2014). Household Survey on Employment. Retrieved from http://www.gks.ru/bgd/regl/b13_30/Main.htm

Prokofiev, V.A. (2006). The scope of the active part of structural changes. Vestnik Saratovskogo gosudarstvennogo socialno ekonomicheskogo universiteta. №.14 (3), p. 119-123.

Rjabcev, V.M., Chudilin, G.I. et al. (2001). Regional statistics. Moscow: MID.

Prokofiev, V.A., Dines, V.A., Teljatnikov N.B. et al. (2008). Statistical methods for the analysis of socio-economic development of the 
administrative-territorial units. Saratov, $288 \mathrm{p}$.

Sukharev, O.S. (2010). Structural problems of the Russian economy. Moscow: Finansy i Statistika.

Shimov, V.N. (1996). Theoretical and methodological foundations of economic restructuring in Belarus. Minsk: $331 \mathrm{p}$.

Tumasjan, A.A. and Vasilevskaja, L.I. (2006).The measurement of structural changes in the industry of the Republic of Belarus. Vestnik Belorusskogo gosudarstvennogo ekonomicheskogo universiteta. №.2,p.59-65.

Chistik,O.F. (2014).Labor market stringency analysis in RF regions. Vestnik Samarskogo gosudarstvennogo ekonomicheskogo universiteta. No.2,pp. 104-109.

Dietrich,A. (2009).Does Growth Cause Structural Change, or Isitthe Other Way Round? A Dynamic Panel Data Analysis for Seven OECD Countries. Jena Research Papers in Economics. Retrieved from http://econpapers.repec.org/paper/jrpjrpwrp/2009-034. $\mathrm{htm}$

Driver, C. and Saw, Ch.-W. (1996). Performance of Structural Change Indices: Analysis Using Real and Simulated Data. Applied Economic Letters. vol.3, pp. 187-188.

Stoikov, V. (1966). Some Determinants of the Level of Frictional Unemployment: A Comparative Study. International Labour Review. vol. 93, pp.530-549. 